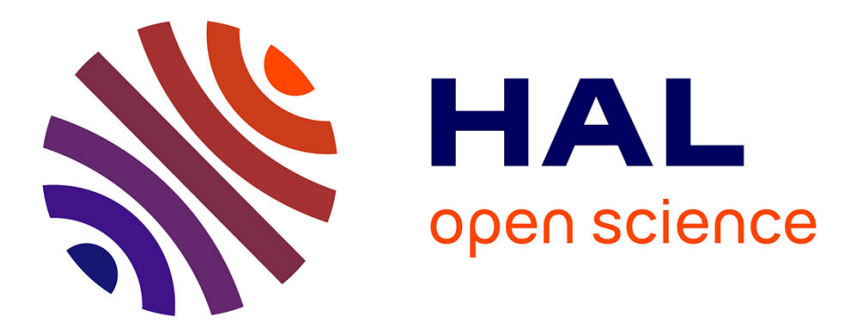

\title{
Synthesis of alumina-metal nanocomposites by mechanical alloying
}

D. Osso, Gérard Le Caër, S. Begin-Colin, A. Mocellin, P. Matteazzi

\section{To cite this version:}

D. Osso, Gérard Le Caër, S. Begin-Colin, A. Mocellin, P. Matteazzi. Synthesis of alumina-metal nanocomposites by mechanical alloying. Journal de Physique IV Proceedings, 1993, 03 (C7), pp.C71407-C7-1412. 10.1051/jp4:19937216 . jpa-00251851

\section{HAL Id: jpa-00251851 https://hal.science/jpa-00251851}

Submitted on 1 Jan 1993

HAL is a multi-disciplinary open access archive for the deposit and dissemination of scientific research documents, whether they are published or not. The documents may come from teaching and research institutions in France or abroad, or from public or private research centers.
L'archive ouverte pluridisciplinaire HAL, est destinée au dépôt et à la diffusion de documents scientifiques de niveau recherche, publiés ou non, émanant des établissements d'enseignement et de recherche français ou étrangers, des laboratoires publics ou privés. 


\title{
Synthesis of alumina-metal nanocomposites by mechanical alloying
}

\author{
D. OSSO, G. LE CAER, S. BEGIN-COLIN, A. MOCELLIN and P. MATTEAZZI*
}

LSG2M, URA 159 du CNRS, Ecole des Mines, 54042 Nancy cedex, France

* Dipartimento di Scienze e Tecnologie Chimiche, Università degli Studi di Udine, via del Cotonificio 108, Udine, Italy

The synthesis of nanometer-sized $\alpha$-Al2 $\mathrm{O}_{3}$-metal composites can be performed by room temperature ball-milling of mixtures of metal-oxides and aluminium as shown by Matteazzi and Le Caër. The average crystallite size of the alumina-metal composite so obtained is in general about $10 \mathrm{~nm}$. Such composites may also be prepared by direct grinding of a mixture of $\alpha-\mathrm{Al}_{2} \mathrm{O}_{3}$ and of a metal or an alloy. The present work is devoted to the study of the reaction mechanisms by X-Ray diffraction and ${ }^{57} \mathrm{Fe}$ Mössbauer spectroscopy for the $\alpha-\mathrm{Al}_{2} \mathrm{O}_{3}-\mathrm{Cr}, \alpha-\mathrm{Al}_{2} \mathrm{O}_{3}-\mathrm{Fe}, \alpha-\mathrm{Al}_{2} \mathrm{O}_{3}-(\mathrm{Fe}-\mathrm{Cr})$ and $\alpha-\mathrm{Al}_{2} \mathrm{O}_{3}-\mathrm{Ti}$ systems. Mössbauer spectroscopy shows that non-completely reduced $\mathrm{Fe}$, partly in the form of $\mathrm{Fe}^{2+}$, still exists at the end of the synthesis and belongs to a ternary Al-Fe-O oxide in $\alpha-\mathrm{Al}_{2} \mathrm{O}_{3}-\mathrm{Fe}$ composites although it cannot be indexed by $\mathrm{X}$-Ray diffraction. The $\mathrm{Fe}^{2+}$ component is mainly associated with iron environments in or similar to those of hercynite. Species like $\mathrm{Fe}^{3+}$ in $\mathrm{Al}_{2} \mathrm{O}_{3}$ or in grain boundaries are observed, $\mathrm{Fe}^{4+}$ and $\mathrm{Fe}_{0}$ cannot be excluded. Differences are obtained by reactive milling and by direct milling the reaction products. Reactive milling of $\mathrm{Al}-\mathrm{TiO}_{2}$ (anatase) yields $\alpha-\mathrm{Al}_{2} \mathrm{O}_{3}-\mathrm{Ti}$ nanocomposites. The transient formation of a high-pressure orthorhombic form of $\mathrm{TiO}_{2}$ of the $\alpha-\mathrm{PbO}_{2}$ type is observed.

\section{1- INTRODUCTION}

Much attention has been devoted to the aim of combining metal to ceramics in order to generate new materials with improved properties. Several processes have been already investigated. More recently, mechanical alloying as dry reactive milling [1] has been used to synthesize various types of materials (carbides, intermetallics, amorphous, dispersed phase materiais, etc...)[2,3]. This process as described by Matteazzi and Le Caër [4] produces also alumina-metal composite powders by reactive milling of aluminium and metal oxides :

$$
2 \mathrm{Al}+\mathrm{M}_{2} \mathrm{O}_{3} \rightarrow \mathrm{Al}_{2} \mathrm{O}_{3}+2 \mathrm{M} \quad \mathrm{M}: \text { metal }(\mathrm{Fe}, \mathrm{Cr}, \text { etc...) }
$$

Such displacement reactions between other metal-oxide systems have been also reported elsewhere $[5,6]$. Moreover, the crystallite size of such alumina-metal composite powders after suitable time of milling is about 10-20nm.

The following systems have been investigated in this work : $\mathrm{Al}_{2} \mathrm{O}_{3}-\mathrm{Cr}, \mathrm{Al}_{2} \mathrm{O}_{3}-\mathrm{Fe}, \mathrm{Al}_{2} \mathrm{O}_{3}-(\mathrm{Fe}-\mathrm{Cr})$ and $\mathrm{Al}_{2} \mathrm{O}_{3}-\mathrm{Ti}$ (table 1). The reduction of the metal oxide by aluminium is followed step by step by $X$-Ray diffraction as well as Mössbauer spectroscopy for iron containing systems which is more sensitive to identify the transient and minor phases. Direct grinding of reaction products is conducted to compare with reactive milling.

Table 1: reactions and corresponding thermodynamic data

\begin{tabular}{|c|c|c|}
\hline reaction & $\Delta \mathrm{H}_{\mathrm{r}}(\mathrm{kJ} / \mathrm{mol})$ & $\mathrm{Tad}(\mathrm{K})^{*}$ \\
\hline $2 \mathrm{Al}+\mathrm{Cr}_{2} \mathrm{O}_{3}->\mathrm{Al}_{2} \mathrm{O}_{3}+2 \mathrm{Cr}(1)$ & 535 & 2584 \\
\hline $2 \mathrm{Al}+\mathrm{Fe}_{2} \mathrm{O}_{3}->\mathrm{Al}_{2} \mathrm{O}_{3}+2 \mathrm{Fe}(2)$ & 850 & 3086 \\
\hline $2 \mathrm{Al}+0.862 \mathrm{Fe}_{2} \mathrm{O}_{3}+0.138 \mathrm{Cr}_{2} \mathrm{O}_{3}->\mathrm{Al}_{2} \mathrm{O}_{3}+2(\mathrm{Fe}-\mathrm{Cr})(3)$ & 806 & \\
\hline $4 \mathrm{Al}+3 \mathrm{TiO}_{2}->2 \mathrm{Al}_{2} \mathrm{O}_{3}+3 \mathrm{Ti}(4)$ & 526 & \\
\hline "calculated as reported by $[7]$ & \multicolumn{2}{|}{}
\end{tabular}




\section{2- EXPERIMENTAL MATERIALS AND PROCEDURE}

Starting high purity $(>99.9 \%)$ powder materials were $\alpha-\mathrm{Al}_{2} \mathrm{O}_{3}(\phi=0.6 \mu \mathrm{m})$, iron oxide $\left(\mathrm{Fe}_{2} \mathrm{O}_{3}\right)(\phi=0.5 \mu \mathrm{m})$, chromium oxide $\left(\mathrm{Cr}_{2} \mathrm{O}_{3}\right)(\phi=0.5 \mu \mathrm{m})$, titanium oxide $\left(\mathrm{TiO}_{2}\right.$ anatase $)(\phi=5 \mu \mathrm{m})$ and metallic aluminium $(\phi=1.3 \mu \mathrm{m})$. The powders mixtures were milled in the stoichiometric proportions (table 1 ) in a planetary mill (Fritsch pulverisette 7) under argon atmosphere with various powder to ball weight ratios (PBR). Grinding utensils ( 7 balls $[\phi=15 \mathrm{~mm}]$ and vials) were steel $(Z 30 \mathrm{C} 13)$ or tungsten carbide (WC). Milling was performed for as long as to obtain nanometer sized crystallites. The resulting products have all been characterized by $X$ ray diffraction using CoK $\alpha$ radiation. $57 \mathrm{Fe}$ Mössbauer spectroscopy (MS) was used in transmission geometry with a ${ }^{57} \mathrm{Co}$ in Rh matrix. All spectra were recorded at room temperature. Only qualitative observations of spectra are presented here. The mean crystallite size $(\langle\mathrm{d}\rangle)$ was calculated using the full width at half maximum ( $F W H M$ ) of $X$-ray peaks corrected by the instrumental broadening ( $F W H M=0,30$ ) as described in other reports [4]. High resolution magic angle spinning nuclear magnetic resonance (MAS-NMR) has been performed in order to study $\mathrm{Al}$ species coordination in the system $\mathrm{Al}_{2} \mathrm{O}_{3}-\mathrm{Cr}$. Local chemical analyses were carried out using an electron microprobe. Finally, metallographic observations of sectioned particles were made.

\section{3-RESULTS AND DISCUSSION}

\section{3-1 synthesis of $\mathrm{Al}_{2} \mathrm{O}_{3}-\mathrm{Cr}$ composite powders}

Grinding of the Al- $\mathrm{Cr}_{2} \mathrm{O}_{3}$ powders is performed with tungsten carbide tools, with a PBR of $(1 / 40)$ and for different times ( $8 \mathrm{~min}$ to $3 \mathrm{~h}$ ). Diffraction peaks of alumina and chromium appear rapidly. An almost complete reaction is reached after 10-15 minutes of milling without transient phases(fig1). Such a quick reaction rate has been noticed by SCHAFFER et al. [8] for other systems. All chromium oxide diffraction peaks disappear after milling during $1 \mathrm{~h} 30$. After milling during 3 hours the mean crystallite size is $8 \mathrm{~nm}$. Final phases identified by XRD are $\alpha-\mathrm{Al}_{2} \mathrm{O}_{3}$, metallic chromium and a weak proportion of WC due to grinding pollution. The $\alpha-\mathrm{Al}_{2} \mathrm{O}_{3}$ diffraction peaks are sligtly shifted and this is attributed to some dissolved $\mathrm{Cr}^{3+}$ in alumina. MAS-NMR on a sample milled during 2 hours reveals (fig 2) a chemical shift at 10ppm characteristic of an oxygen octahedral environment of Al atoms [9] and corresponds to $\alpha$-Alumina. A second chemical shift is observed at $\approx 30-40 \mathrm{ppm}$. Such chemical shift has been assigned to a pentahedral oxygen coordination by CRUICKSHANK et al. [10]. This latter coordination could be ascribed to Al atoms in grain boundaries. The volumic fraction of grain boundaries in the whole material can be estimated [11] by the crystallite size and is with a mean size of $8 \mathrm{~nm}$ about $30 \mathrm{vol} . \%$.

Total synthesis of alumina-chromium powders by Milling of aluminium and chromium oxide in a steel grinding medium was not possible, even with a PBR of (1/40) and 4 hours milling. The slow rate of reaction (1) can be explained by a different kinetic energy of balls in movement in the vial. Kinetic energy is connected to the density of material $\left(7,3 \mathrm{~g} / \mathrm{cm}^{3}\right.$ for steel and $15.6 \mathrm{~g} / \mathrm{cm}^{3}$ for WC). Moreover, the heat of reaction (1) released at the beginning of reaction is not important enough to propagate the reaction.

XRD patterns of reactively milled products and the direct milled $\mathrm{Al}_{2} \mathrm{O}_{3}-\mathrm{Cr}$ powders are quite similar although some XRD peaks aren't exactely in the same $2 \theta$ position.

\section{3-2 synthesis of $\mathrm{Al}_{2} \mathrm{O}_{3}-\mathrm{Fe}$ composite powders}

Al- $\mathrm{Fe}_{2} \mathrm{O}_{3}$ powders are milled in steel grinding medium and with differents PBR from $(1 / 10)$ to $(1 / 40)$. Mössbauer spectroscopy of powders milled with a PBR of $(1 / 10)(\mathrm{fig} 3)$ points out that reaction (2) takes place between 20-25 minutes of grinding. Mössbauer spectrum at 25 minutes presents iron sextuplet and a weak central non magnetic dissymetric component (quadrupolar splitting: $2 \mathrm{~mm} / \mathrm{s}$ ) which is attributed to some non reduced $\mathrm{Fe}^{2+}$ belonging to hercynite $\left(\mathrm{FeAl}_{2} \mathrm{O}_{4}\right)$. Iron sextuplet with a reduced hyperfine field is observed and corresponds to some aluminium dissolved in iron. Spectrum, after 30 minutes milling, shows low intensity sextuplet of iron and a high intensity symmetric doublet. This latter component was identified as hercynite $\left(\mathrm{FeAl}_{2} \mathrm{O}_{4}\right)$. However, diffraction peaks are slightly shifted with respect to the peak positions given by the JCPDS file. Longer time of milling yields a reduction of the proportion of the hercynite type oxide as shown by the 40 minutes milling time spectrum. Moreover, it can be noted that the central component becomes asymmetric. A steady state is reached after 1 hour of milling. Final spectrum, recorded for 4 hours, exhibits sextuplet of iron, a central non magnetic asymmetric component with a more intense contribution close to the zero velocity, a iron sextuplet with a reduced hyperfine field. This non magnetic component may be partly attributed to $\mathrm{Fe}^{2+}$ in environments similar to those of iron in hercynite. The main central peak of the doublet is likely the superposition of various contributions which may be $\mathrm{Fe}^{3+}, \mathrm{Fe}^{4+}$ or even $\mathrm{Fe}_{0}$. They are likely located in grain boundaries or at the interface between iron and alumina grains. The asymmetric component is indeed quite similar to the Mössbauer central subspectra which have been reported for iron implanted in alumina [12] and for ion beam mixing of $\mathrm{Al}_{2} \mathrm{O}_{3}-\mathrm{Fe}$ interface [13].

Mössbauer spectra of Al-Fe2 $\mathrm{O}_{3}$ mixtures milled with a PBR of $(1 / 20)$ during 30 minutes or 4 hours (fig 4 ) exhibit the same components as a spectrum of powders milled during 4 hours with a PBR of $(1 / 10)$. Major 
differences lay on the intensities of the two central doublets which were smaller. No transient phase like before was observed. The spectra of powders milled with a PBR smaller than (1/20) present no differences with the latter spectra.

The presence of a transient type hercynite oxide, which is only observed inthe case of PBR of $(1 / 10)$, could be explained by the mixing of alumina and metallic iron phases with a clear influence of temperature for that particular PBR. The temperature rises up in the beginning of the reaction and since calories from the exothermic reaction cannot be evacuated fast enough through the vials due to the important amount of reacting powders in there. However, this oxide disapears for longer milling times as the temperature decreases. Such temperature rise up and decrease was reported by $[8,14]$ for this type of reaction. Moreover, after long milling time an amount of iron remains in state of $\mathrm{Fe}^{2+}$.

Mössbauer spectra of $\mathrm{Al}_{2} \mathrm{O}_{3}+\mathrm{Fe}$ powder mixture milled directly (fig 5 ) show only one iron sextuplet and a low intensity central doublet which is asymmetric as discussed previously.

\section{3-3 synthesis of $\mathrm{Al}_{2} \mathrm{O}_{3}-(\mathrm{Fe}-\mathrm{Cr})$ composite powders}

Al- $-\mathrm{Fe}_{2} \mathrm{O}_{3}-\mathrm{Cr}_{2} \mathrm{O}_{3}$ powders were milled in steel grinding medium with a PBR of (1/20). The proportion of iron and chromium oxides was chosen in order to obtain an iron metallic phase with $13 w t \%$ of chromium (table 1). The choice of a composition of $13 w t \%$ chromium is made to minimize the effect of pollution by the grinding medium.

The rate of reaction (3) as shown by MS (fig 6) is slower than that of reaction (2). The presence of chromium oxide moderates the rate of reaction (2). The reduction of iron oxide releases energy which is used to reduce chromium oxide. Total reduction of iron is achieved after milling during 27 minutes. After milling during 4 hours the iron metallic phase contains $\approx 10$ at $\%$ of $\mathrm{Cr}$ in solution [15] and ,by XRD, $\alpha$-alumina and $\alpha$-iron are identified. Electron microprobe analyses of milled powders confirm the stable amount of 10at\% chromium and that Aluminium dissolved in the Fe-Cr phase is very small (table 2). The oxygen content indeed proves that we are dealing with the metallic phase. Analyses on powders milled for more than 2 hours were not possible because of the mixing of the two phases (metallic and ceramic)(fig 7) which are too fine for the microprobe spot. However, after milling during 15 minutes the oxide and metallic particles are not well mixed (fig 7). This step corresponds to the beginning of the reaction. Longer milling time is necessary to homogeneize the mixture and to reduce the crystallite size to a nanometer range.

Table 2: electron microprobe analyses of the metallic phase

\begin{tabular}{|c|c|c|c|c|}
\hline milling time & $\mathrm{Fe}(\mathrm{at} \%)$ & $\mathrm{Al}(\mathrm{at} \%)$ & $\mathrm{Cr}(\mathrm{at} \%)$ & $\mathrm{O}(\mathrm{at} \%)$ \\
\hline 30 minutes & 88.80 & 0.98 & 10.22 & 0.00 \\
\hline 1 hour & 90.19 & 0.36 & 9.44 & 0.00 \\
\hline 2 hours & 89.89 & 0.21 & 9.90 & 0.00 \\
\hline
\end{tabular}

Direct milling of alumina, iron and chromium during 4 hours with a PBR=(1/20) in steel grinding medium yields a low alloyed iron phase with $<3 a \%$ of chromium. Some unalloyed chromium therefore remains eitheir as separate metallic phase or dissolved in the alumina. The presence of metallic chromium in the system can't be resolved by XRD due to broad peaks and to the small overall amount of chromium.

\section{3-4 synthesis of $\mathrm{Al}_{2} \mathrm{O}_{3}$-Ti composites powders}

The reduction of $\mathrm{TiO}_{2}$ (anatase) to Ti by aluminum is followed step by step by the XRD patterns (figure 8 ) which allow to conclude that 8 hours are necessary to reach an almost complete transformation. The final products of the reaction are not obtained directly, intermediate phases are formed : a high-pressure form of $\mathrm{TiO}_{2}$ which has an orthorhombic $\alpha-\mathrm{PbO}_{2}$ type structure appears at the beginning of milling and disappears rapidly, so does an AITi intermetallic compound. To confirm the formation of this high-pressure form of $\mathrm{TiO}_{2}$ [16][JCPDS file 23-1446], we have milled anatase-TiO 2 during 30 minutes and one hour respectively. After 30 minutes, we identify the rutile and high-pressure orthorhombic forms of $\mathrm{TiO}_{2}$ and after one hour the highpressure form tends to disappear and the major phase is the rutile one.

Analyses with an electron microprobe in a compacted powder product after milling during 6 hours show that the final product is very homogeneous (as confirmed by X-ray images). After 6 hours, the major constituents are $\mathrm{Al}_{2} \mathrm{O}_{3}$ and $\mathrm{Ti}$.

\section{4- CONCLUSION}

Synthesis of powders of alumina-metal nanocomposites has been investigated for alumina-(chromium, iron, iron-chromium and titanium) by reactive milling of aluminium and corresponding metal oxide. The reaction takes place only after an incubation milling time which varies from 15 minutes to 1 hour according to the experimental conditions while the reaction needs 1 to 4 hours to be completed. For suitable milling time nanometer-sized crystallites are produced.

A transient phase (a hercynite type oxide) is formed in the alumina-iron system for a powder to ball weight ratio (PBR) of $(1 / 10)$. For smaller PBR no transient phase is observed. Non reduced iron is present, whatever 
the experimental conditions, and belongs to an $\mathrm{Al}-\mathrm{Fe}-\mathrm{O}$ oxide. Moreover, some $\mathrm{Fe}^{3+}, \mathrm{Fe}^{4+}$ or $\mathrm{Fe}_{0}$ may also be present at alumina-iron interfaces or in grain boundaries.

The alumina-titanium system shows two transient phases during the reactive milling. An intermetallic phase (AITi) and a high pressure form of titanium oxide ( $\alpha-\mathrm{PbO}_{2}$ type structure).

The effect of an important volumic proportion of grain boundaries due to a nanometer size crystallite could explain the observation of an unusual coordination of aluminium in alumina which are likely in the grain boundaries.

Direct milling of alumina-metal yields slightly different composite powders.

Acknowledgments : we would like to thank P.DELCROIX for useful help in Mössbauer spectroscopy, A.PIANELLI and M.ZANDONNA for the X-ray diffraction experiments and P.TEKELY and D.CANET (Laboratoire de Methodologie RMN, Université de NANCY I) for the nuclear magnetic resonance work. The work was financially supported by EEC, contract SC1-CT91-0668 (Science Program).

references :

[2] F.H.FROES, JOM january (1989) 25

[3] C.C.KOCH, Annu. Rev. Mater. Sci. 19 (1989)121

[4] P.MATTEAZZI, G.LE CAER, j.of am. ceram. soc. 75 (1992) 2749

[5] G.B.SCHAFFER, P.G.McCORMICK, Met. trans. 21A (1990) 2789

[6] M.PARDAVI-HORVATH, L.TAKACS, Submitted to IEEE Trans. mag. (INTERMAG, 1992)

[7] K.Y.WANG, T.D.SHEN, M.X.QUAN, J.T.WANG, Scripta Met. 26 (1992) 933

[8] G.B.SCHAFFER, P.G.MCCORMICKScripta Met. 23 (1989) 835

[9] R.DUPREE, M.M.LEWIS, M.E.SMITH, J. appl.cryst. 21 (1988)

[10] M.C.CRUICKSHANK, L.S.D.GLASSER, S.A.I.BARAI, I.J.F.,POPLETT, J.Chem.Soc. (1986) 23

[11] G.PALUMBO, S.J.THORPE, K.T.AUST, Scripta Met. 24 (1990) 1347

[12] C.J.McHARGUE, P.S.SKALD, G.C.FARLOW, A.PEREZ, G.MAREST J. of mat. Res. 6 (1991) 2145

[13] A.PEREZ, E.ABONNEAU, G.FUCHS, M.TREILLEUX, C.J.MCHARGUE, D.L.JOSLIN, Nuclear instruments \& methods in physics research $\mathrm{B} 65$ (1992) 129

[14] M.ATZMON, Phys.Rev.Lett. 64 (1990) 487

[15] S.M.DUBIEL, K.KROP, journal de physique colloque C4 supplément au No1235 (1974) 459

[16] R.K.LINDE, P.S.DECARLY, J.Chem.Phys. 1 (1969) 319 


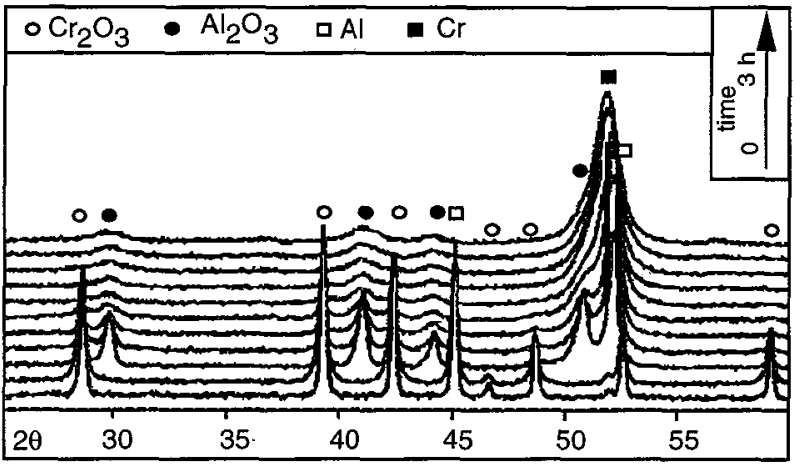

fig 1 : XRD of milled $\mathrm{Al}+\mathrm{Cr}_{2} \mathrm{O}_{3}$.

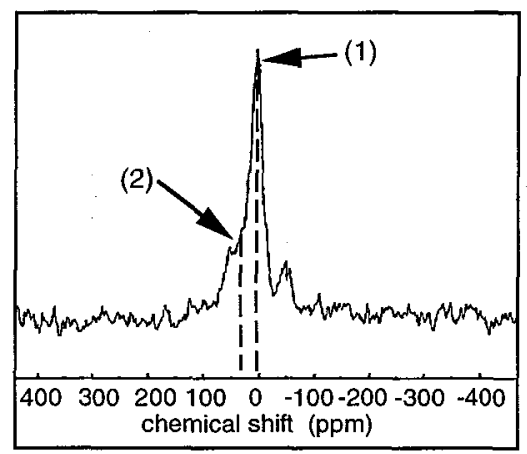

fig 2: NMR of $\mathrm{Al}+\mathrm{Cr}_{2} \mathrm{O}_{3}$ powders milled for 2 hours. Coordination: (1)octahedral (2)pentahedral.

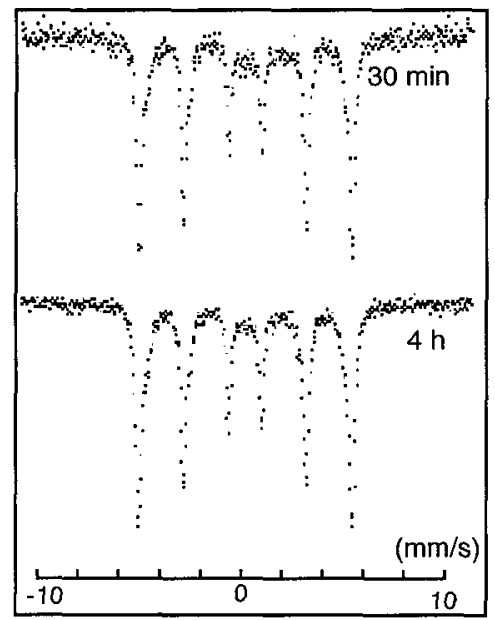

fig 4 : Mössbauer spectrum of milled $\mathrm{Al}+\mathrm{Fe}_{2} \mathrm{O}_{3}$ (PBR 1/10).

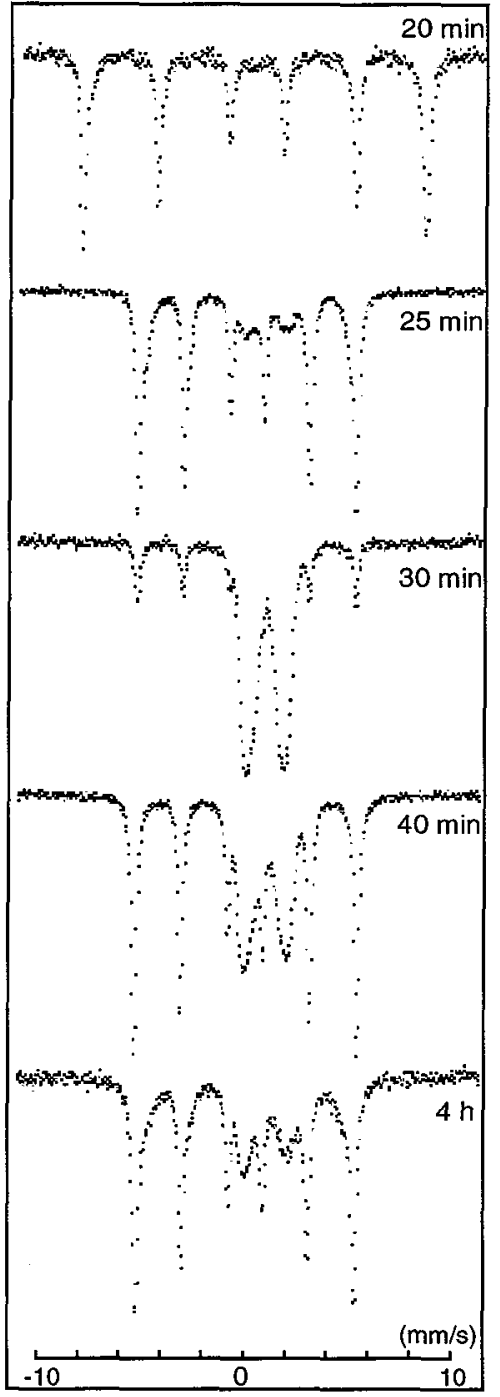

fig 3 : Mössbauer spectra of milled $\mathrm{Al}+\mathrm{Fe}_{2} \mathrm{O}_{3}$ (PBR 1/10).

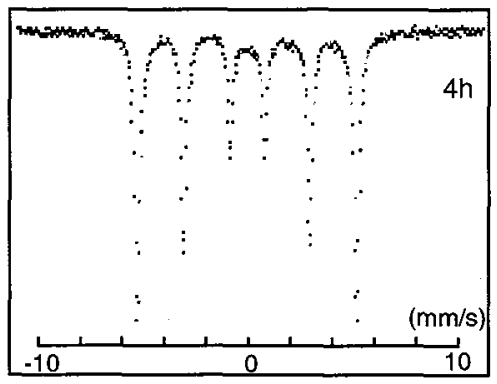

fig 5 : Mössbauer spectrum of milled $\mathrm{Al}_{2} \mathrm{O}_{3}+\mathrm{Fe}$ (PBR 1/10). 


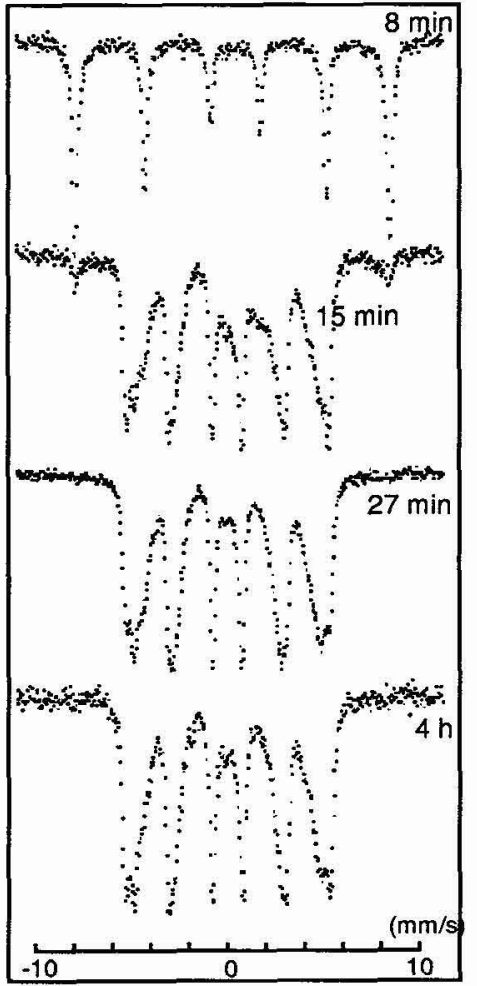

fig $6:$ Mössbauer spectra of milled $\mathrm{Al}+\mathrm{Fe}_{2} \mathrm{O}_{3}+\mathrm{Cr}_{2} \mathrm{O}_{3}$.

fig 7 : milled powders (optical images). $8 \mathrm{~min}(1): \mathrm{Al}+\mathrm{Fe}_{2} \mathrm{O}_{3}+\mathrm{Cr}_{2} \mathrm{O}_{3}$

$15 \mathrm{~min}(2), 1 \mathrm{~h}(3)$ and $4 \mathrm{~h}(4) \mathrm{Al}_{2} \mathrm{O}_{3}+\mathrm{Fe}-\mathrm{Cr}$.

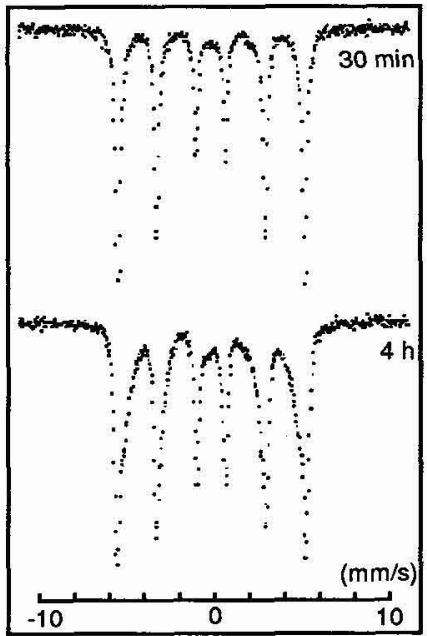

fig 8 : Mössbauer spectra of milled $\mathrm{Al}_{2} \mathrm{O}_{3}+\mathrm{Fe}+\mathrm{Cr}$.

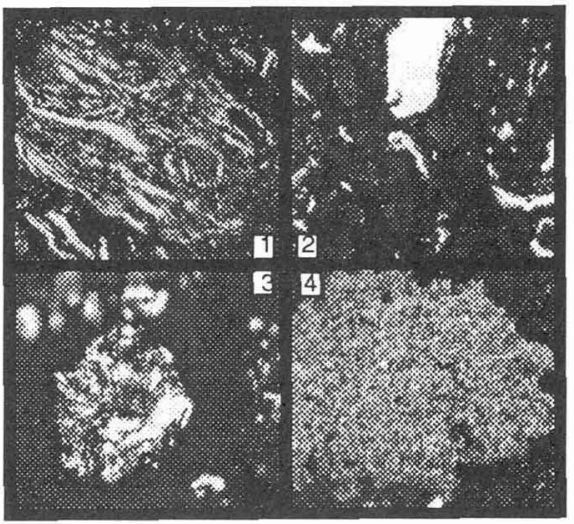

$10 \mu \mathrm{m}$

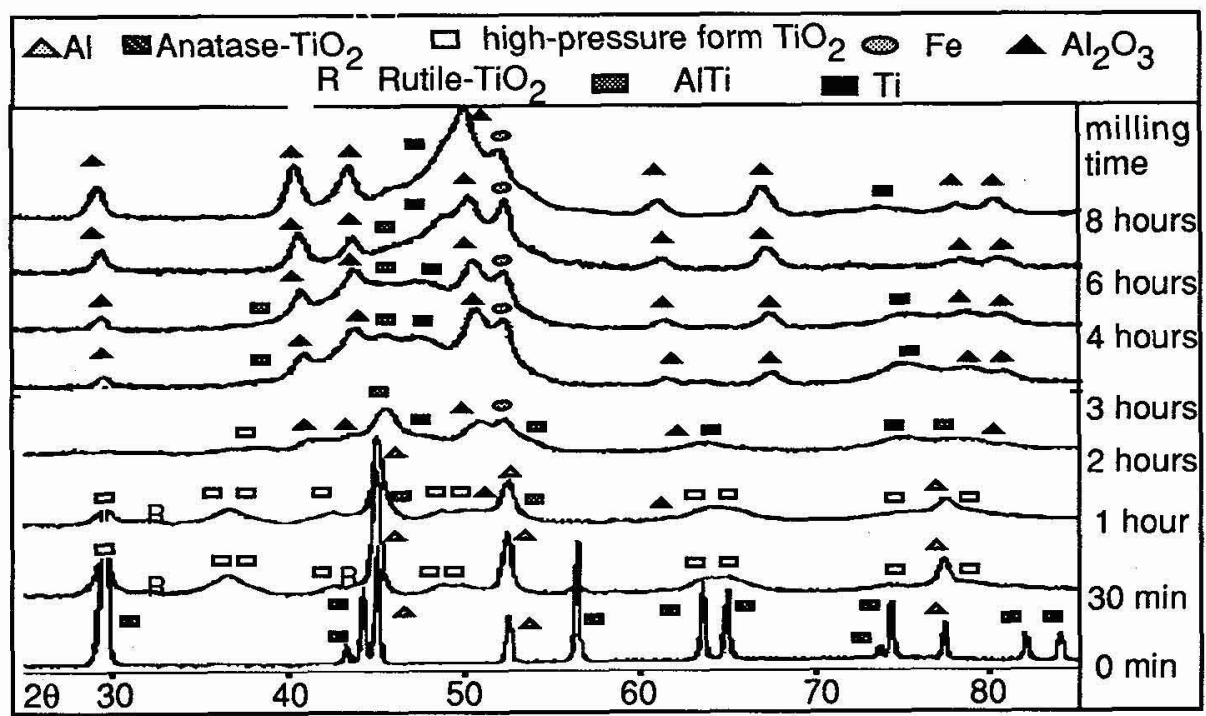

fig 9 : XRD of milled $\mathrm{Al}+\mathrm{TiO}_{2}$ 